\title{
Ipsilateral hypoperfusion caused by intracerebral steal phenomenon after carotid artery stenting: a case report
}

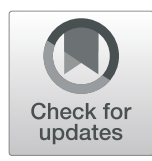

Zhizhong Yan ${ }^{1}$, Zhonghua Shi ${ }^{1}$, Yuhai Wang ${ }^{1}$, Chunlei Zhang ${ }^{1}$, Huize Liu', Jin Cai ${ }^{2}$ and Xin Zhang ${ }^{2 *}$

\begin{abstract}
Background: Abnormal hypoperfusion on the surgical side after carotid artery stenting is rare. Neurological deterioration caused by it is deceptive, which can easily lead to misdiagnosis. The mechanism of hypoperfusion has rarely been demonstrated. We present here a fully studied case with a high probability of intracerebral steal phenomenon.

Case presentation: A 68-year-old male with severe right internal carotid artery stenosis and left internal carotid artery occlusion underwent right stenosis stent implantation. Restlessness and left limb hemiplegia occurred within $24 \mathrm{~h}$ after the procedure, which was similar to hyperperfusion syndrome. However, postoperative computerized tomography perfusion (CTP) revealed abnormal hypoperfusion in the right hemisphere. Transcranial Doppler (TCD) also showed decreased flow velocity in the right middle cerebral artery, and increased flow velocity in the right anterior cerebral artery. We considered that intracerebral steal phenomenon might be the cause, then hypervolemic therapy was accepted and the symptoms completely resolved after 3 days.
\end{abstract}

Conclusions: Ipsilateral hypoperfusion is rarely seen after carotid artery stenting. Intracerebral steal phenomenon may be the underlying mechanism. CTP or TCD is helpful for the early detection of this adverse event.

Keywords: Intracerebral steal phenomenon, Stenting, Endovascular treatment, Carotid artery

\section{Background}

Internal carotid artery (ICA) stenosis is one of the main factors for stroke, and patients with contralateral internal carotid artery occlusion are associated with a higher rate of stroke [1]. The treatment of these patients is challenging, and carotid artery stenting (CAS) is currently recommended for these patients with a greater surgical risk [2]. Perioperative complications such as infarction, hyperperfusion, and cerebral hemorrhage are relatively common [3]. Here, we report a rare postoperative complication in this kind of patient. Hypoperfusion

\footnotetext{
* Correspondence: 147385824@qq.com

${ }^{2}$ Department of Neurosurgery, Jinling Hospital, The First School of Clinical Medicine, Southern Medical University, No. 305 Zhongshan East Road, Jiangsu Province 210002 Nanjing, People's Republic of China

Full list of author information is available at the end of the article
}

appeared on the surgical side after CAS, which resulted in neurological deterioration similar to hyperperfusion syndrome. We suppose that intracerebral steal phenomenon may be a strong candidate for its underlying mechanism.

\section{Case presentation}

A 68-year-old male presented to the outpatient clinic complaining of drowsiness and fatigue for 2 weeks. $\mathrm{He}$ had a history of left-sided cerebral infarction 5 months ago and no hypertension, diabetes, coronary artery disease or atrial fibrillation. Since then, dual antiplatelet and statin therapy was taken and there was no transient ischemic attack. Neurological examination showed right limb dyskinesia along with aphasia. The admission lowdensity lipoprotein cholesterol was $1.64 \mathrm{mmol} / \mathrm{L}$,

(C) The Author(s). 2021 Open Access This article is licensed under a Creative Commons Attribution 4.0 International License, which permits use, sharing, adaptation, distribution and reproduction in any medium or format, as long as you give appropriate credit to the original author(s) and the source, provide a link to the Creative Commons licence, and indicate if changes were made. The images or other third party material in this article are included in the article's Creative Commons licence, unless indicated otherwise in a credit line to the material. If material is not included in the article's Creative Commons licence and your intended use is not permitted by statutory regulation or exceeds the permitted use, you will need to obtain permission directly from the copyright holder. To view a copy of this licence, visit http://creativecommons.org/licenses/by/4.0/ The Creative Commons Public Domain Dedication waiver (http://creativecommons.org/publicdomain/zero/1.0/) applies to the data made available in this article, unless otherwise stated in a credit line to the data. 
preoperative coagulation was normal with prothrombin time (PT) of 11.9 s, activated partial thromboplastin time (APTT) of $27.3 \mathrm{~s}$, international normalized ratio (INR) of 1.04, thromboelastography arachidonic acid (AA) inhibition rate of $96 \%$ and adenosine diphosphate (ADP) inhibition rate of $90 \%$. The electrocardiogram showed sinus tachycardia. Because of claustrophobia, only computed tomography (CT) images could be provided. After admission, onestop computed tomography angiography (CTA)/computed tomography perfusion (CTP) was performed. CTA showed that the Willis circle was well developed (Fig. 1a). CTP showed that cerebral blood volume (CBV) and cerebral blood flow (CBF) in the left hemisphere were lower than those in the right hemisphere, while time to peak (TTP) was significantly higher (Fig. 2b, c and d).

Digital subtraction angiography (DSA) revealed occlusion at the beginning of the left ICA and $75 \%$ stenosis in the right ICA according to the North American Symptomatic Carotid Endarterectomy Trial criteria (Fig. $1 \mathrm{~b}$ and c). The right ICA stent (XACT 6-8*40 mm, Abbott) implantation was performed after DSA (Fig. 1d). During the procedure, there was no significant decrease in blood pressure or heart rate, nor any neurological deterioration. Unfortunately, $8 \mathrm{~h}$ after CAS, the patient developed restlessness, accompanied by a marked increase in blood pressure $(170 / 100 \mathrm{mmHg})$. After the exclusion of intracranial hemorrhage by CT, sedation and antihypertensive treatment were used, and the blood pressure was controlled below $120 / 80 \mathrm{mmHg}$. However, the patient developed left limb hemiplegia $24 \mathrm{~h}$ after the procedure. Then one-stop CTA/CTP was performed again. Intracranial vessels were comparable to that before CAS (Fig. 2a and e). CTP showed CBV and CBF in the left hemisphere were improved and TTP was reduced significantly. But CBV and CBF in the right hemisphere were not only lower than pre-operation, but also lower than that in the left hemisphere (Fig. 2f, g and h). Dynamic Transcranial Doppler (TCD) was also performed. Flow velocity of the right middle cerebral artery (MCA) decreased $24 \mathrm{~h}$ after CAS, while that of the right anterior cerebral artery (ACA) increased significantly (Table 1). We supposed that hypoperfusion in the right hemisphere might be caused by left-to-right blood theft. Then hypervolemic treatment (intravenous infusion of saline $3000 \mathrm{ml}$ per day) was accepted and the blood pressure was maintained above 140/90 $\mathrm{mmHg}$. After 3 days, the patient's restlessness and left limb hemiplegia were completely relieved. No recurrence of cerebral ischemia occurred during 3 months of telephone follow-up.

\section{Discussion and conclusion}

Carotid artery occlusion occurs in $5-15 \%$ of patients with carotid artery stenosis [4]. In recent years, CAS has been increasingly used as an alternative for patients at high risk of carotid endarterectomy, including those with carotid artery occlusion [5]. Hyperperfusion, cerebral hemorrhage and stroke are common perioperative complications, however, postoperative hypoperfusion on the CAS side is rarely reported.

There was no neurological deterioration during and after procedure, so infarction caused by intraoperative emboli could be excluded. In patients with carotid artery occlusion, the flow velocity of ipsilateral and contralateral MCA increased significantly in the early stage after CAS [6]. And Sadato et al. also found that CBF in both hemispheres increased after unilateral CAS [7]. However, in this case, the flow velocity of MCA decreased, and hypoperfusion appeared on the treated side after CAS. We consider that the occurrence of hypoperfusion is probably caused by left-to-right intracerebral steal phenomenon.

Intracerebral steal phenomenon is a pathological process in which a large amount of blood flows in reverse through a vascular bed with lower resistance, resulting in reduced blood supply of other adjacent arteries and corresponding clinical symptoms [8]. This phenomenon has been mainly reported in subclavian artery occlusion or arteriovenous malformations [9]. In this case, preoperative ischemia in the left hemisphere was more severe than that in the right side according to CTP, so the capillary in the left hemisphere may be

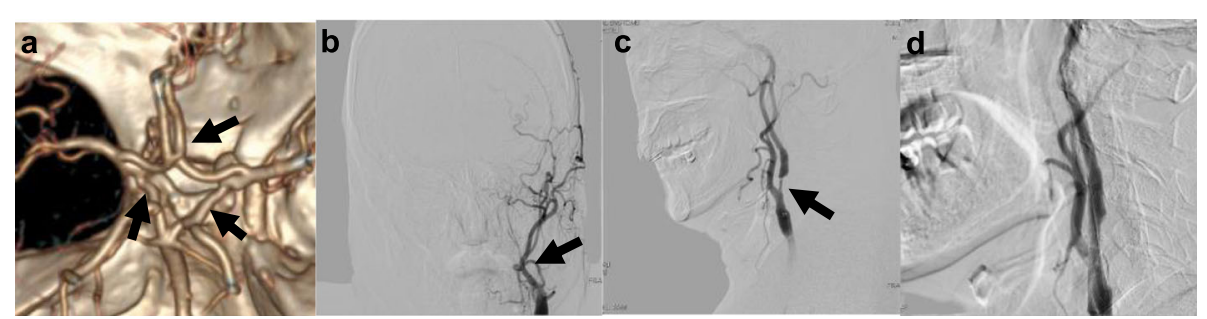

Fig. 1 a Anterior communicating artery and bilateral posterior communicating artery are well developed (arrow). b DSA shows left ICA occlusion (arrow). c DSA shows right ICA severe stenosis (arrow). d DSA shows right ICA following carotid artery stenting 

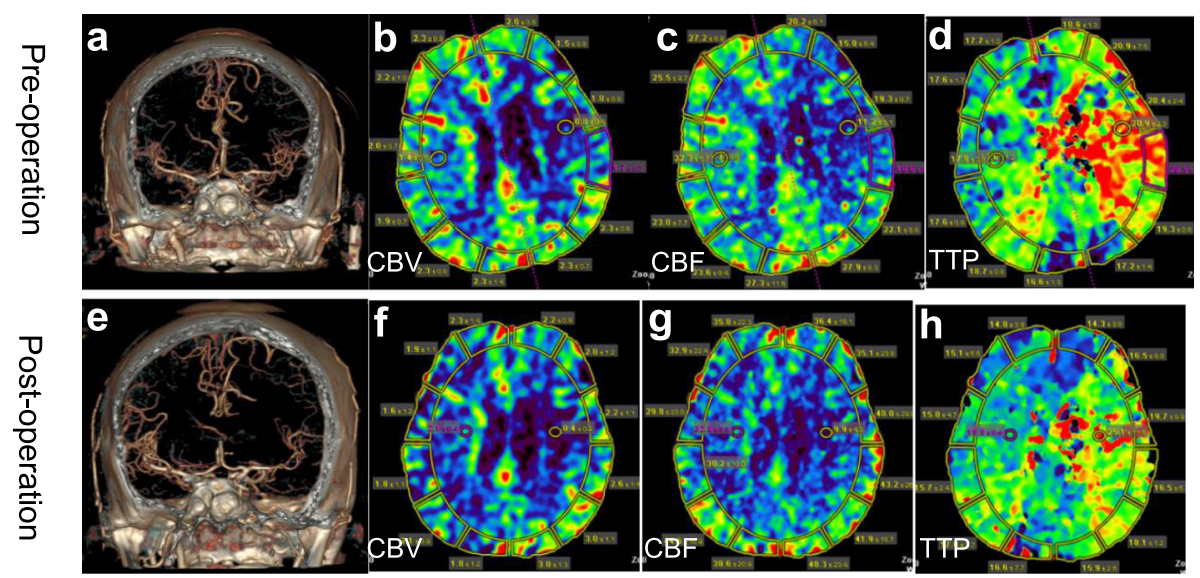

Fig. $\mathbf{2}$ a and e CTA before and 24 hours after stenting show the intracranial vessels are similar. b, cand $\mathbf{d}$ CTP before operation. $\mathbf{f}, \mathbf{g}$ and $\mathbf{h}$ CTP 24 hours after operation

extremely dilated. When the right ICA stenosis was relieved, more blood flow may pass through the anterior communicating artery into the left hemisphere with lower resistance, resulting in hypoperfusion on the right side.

Although there are few reports about intracerebral steal phenomenon, it may not be uncommon, mainly because its symptoms are similar to other common complications, which can easily lead to misdiagnosis. If intracerebral steal phenomenon can't be detected in time, it may lead to ischemia aggravation, or even infarction. Dynamic TCD monitoring in the early stage after CAS may be helpful. If the MCA flow velocity on the treated side decreases abnormally after CAS, the existence of intracerebral steal phenomenon should be highly suspected.

In conclusion, hypoperfusion caused by intracerebral steal phenomenon is a rare complication after CAS. It can cause neurological deterioration, but symptoms are deceptive. Postoperative dynamic TCD monitoring and perfusion CT are helpful for early detection to prevent this harmful side effect.

Table 1 TCD results before, $24 \mathrm{~h}$ and 3 days after CAS

\begin{tabular}{llll}
\hline Vm $\mathbf{( c m} / \mathbf{s})$ & Pre-operation & $\mathbf{2 4} \mathbf{h}$ after CAS & $\mathbf{3}$ days after CAS \\
\hline R-ICA & 164.4 & 39.5 & 28.7 \\
L-ICA & -- & -- & -- \\
R-MCA & 50.7 & 46.5 & 72.5 \\
L-MCA & 17.8 & 24.6 & 23.2 \\
R-ACA & 30.2 & 97.8 & 68.4 \\
L-ACA & 27.5 & 38.5 & 37.3 \\
\hline
\end{tabular}

Abbreviations: Vm mean blood flow velocity

\section{Abbreviations}

CT: Computed tomography; CTP: Computed tomography perfusion; CTA: Computed tomography angiography; CBV: Cerebral blood volume; CBF: Cerebral blood flow; TTP: Time to peak; TCD: Transcranial doppler; DSA: Digital subtraction angiography; ICA: Internal carotid artery; MCA: Middle cerebral artery; ACA: Anterior cerebral artery; CAS: Carotid artery stenting

\section{Acknowledgements}

The authors would like to thank the patient for letting us publish his case and all the contributors for their input and work.

\section{Authors' contributions}

All authors were involved in the clinical care of the patient. Conception and design: XZ and ZHS; Acquisition the materials and data: ZZY, YHW, CLZ, HZL; Drafted the manuscript ZZY; JC and XZ critically revised the manuscript for important intellectual content. All authors read and approved the final manuscript.

\section{Funding}

This work was supported by National Natural Science Foundation of China (81400332). The funders had no role in study design, data collection and analysis, decision to publish, or preparation of the manuscript.

Availability of data and materials

The data used and analyzed during the present study are available from the corresponding author on reasonable request.

\section{Declarations}

Ethics approval and consent to participate

We confirm that we have read the journal's position on issues involved in ethical publication and affirm that this report is consistent with those guidelines. As this is a case report describing clinical observations, ethics approval was waived.

\section{Consent for publication}

Written informed consent for publication of clinical details and any accompanying images were obtained from the patient himself and his daughter.

\section{Competing interests}

The authors declare that they have no competing interests. None of the authors has any conflict of interest to disclose. 


\section{Author details}

'Department of Neurosurgery, The 904 th Hospital of the Joint Logistics Support force of Chinese People's Liberation Army, No. 101 North Xinyuan Road, Jiangsu Province 214000 Wuxi, People's Republic of China.

${ }^{2}$ Department of Neurosurgery, Jinling Hospital, The First School of Clinical Medicine, Southern Medical University, No. 305 Zhongshan East Road,

Jiangsu Province 210002 Nanjing, People's Republic of China.

Received: 1 November 2020 Accepted: 20 April 2021

Published online: 08 May 2021

\section{References}

1. AbuRahma AF, Metz MJ, Robinson PA. Natural history of $>$ or $=60 \%$ asymptomatic carotid stenosis in patients with contralateral carotid occlusion. Ann Surg. 2003:238(4):551-61 discussion 561 - 552.

2. Kokkinidis DG, Chaitidis N, Giannopoulos S, Texakalidis P, Haider MN, Aronow HD, Giri JS, Armstrong EJ. Presence of contralateral carotid occlusion is associated with increased periprocedural stroke risk following CEA but not CAS: a meta-analysis and meta-regression analysis of 43 studies and 96,658 patients. J Endovasc Ther. 2020;27(2):334-44.

3. Ederle J, Dobson J, Featherstone RL, Bonati LH, van der Worp HB, de Borst GJ, Lo TH, Gaines P, Dorman PJ, Macdonald S, et al. Carotid artery stenting compared with endarterectomy in patients with symptomatic carotid stenosis (International Carotid Stenting Study): an interim analysis of a randomised controlled trial. Lancet. 2010;375(9719):985-97.

4. Faggioli G, Pini R, Mauro R, Freyrie A, Gargiulo M, Stella A. Contralatera carotid occlusion in endovascular and surgical carotid revascularization: a single centre experience with literature review and meta-analysis. Eur J Vasc Endovasc Surg. 2013;46(1):10-20.

5. Ricotta JJ 2nd, Upchurch GR Jr, Landis GS, Kenwood CT, Siami FS, Tsilimparis $\mathrm{N}$, Ricotta JJ, White RA. The influence of contralateral occlusion on results of carotid interventions from the Society for Vascular Surgery Vascular Registry J Vasc Surg. 2014;60(4):958-64. discussion 964 - 955.

6. Yan Z, Yang M, Niu G, Zhang B, Tong X, Guo H, Zou Y. Hemodynamic surveillance of unilateral carotid artery stenting in patients with or without contralateral carotid occlusion by TCD/TCCD in the early stage following procedure. Front Neurol. 2019;10:958

7. Sadato A, Maeda S, Hayakawa M, Adachi K, Toyama H, Nakahara I, Hirose Y. Carotid stenting for unilateral stenosis can increase contralateral hemispheric cerebral blood flow. J Neurointerv Surg. 2018;10(4):351-4.

8. Wang D, Li Z, Zheng X, Cong H, Zhang T, Wang Z, Wang Y, He J. Head and neck $C T$ angiography to assess the internal carotid artery stealing pathway. BMC Neurol. 2020;20(1):334.

9. Randhawa N, Squires JP, Heran MKS, Mann SK. Where did the clot go? An unusual complication of mechanical thrombectomy caused by malignancy related subclavian steal phenomenon in a patient with acute basilar artery occlusion. J Neurointerv Surg. 2017;9(6):e22.

\section{Publisher's Note}

Springer Nature remains neutral with regard to jurisdictional claims in published maps and institutional affiliations.

Ready to submit your research? Choose BMC and benefit from:
- fast, convenient online submission
- thorough peer review by experienced researchers in your field
- rapid publication on acceptance
- support for research data, including large and complex data types
- gold Open Access which fosters wider collaboration and increased citations
- maximum visibility for your research: over 100M website views per year
At BMC, research is always in progress.
Learn more biomedcentral.com/submissions

